\title{
Isoflavones derived from Glycine max (L.) Merr. in the treatment of vaginal atrophy: A new frontier
}

\author{
Isoflavonas derivadas do Glycine max (L.) MerR. no tratamento da atrofia vaginal: \\ NOVA FRONTEIRA
}

Sônia Maria Rolim Rosa Lima ${ }^{1 *}$, Adriana Bittencourt Campaner ${ }^{1}$, Antonio Pedro Flores Auge ${ }^{1}$

${ }^{1}$ Department of Obstetrics and Gynecology, Faculdade de Ciências Médicas da Santa Casa de São Paulo, São Paulo, SP, Brazil

lima@silber.com.br

During the climacteric, many changes take place, caused both by the decrease of estrogens and other hormones and by the effects of aging itself. ${ }^{1}$ Complaints of vasomotor alterations, sleep disturbance, mood changes, and genitourinary symptoms (GUS) are common. GUS affect up to $50 \%$ of women in this period. They may be chronic and progressive and their lifelong improvement is unlikely. They can range from mild to severe and are not exclusive to sexually active women. Despite this, many are unaware that such symptoms result directly from the decline in estrogen associated with menopause, and that there are treatments available. ${ }^{2}$

Due to a common embryological origin, the bladder, the urethra and the genitals have similar responses to hormonal changes, especially to estrogens. The atrophic process that accompanies the hypoestrogenism can be verified in the epithelium and in the pelvic support tissues. The mucous membranes become thinner, also causing genital prolapse, vaginal and urinary symptoms become frequent and intense, the vaginal microbiota changes, and vaginal $\mathrm{pH}$ becomes more alkaline influencing women's lives globally. ${ }^{3}$

Despite the many safe and effective options for treating the changes caused by vulvovaginal atrophy (VVA), only a minority of women (about $25 \%$ in the Western world and probably much less in other areas) seek medical help. ${ }^{4}$ One of the possible reasons for this behavior is the adverse publicity (not currently justified) disclosed in recent years for the use of hormone replacement therapy (HRT) in menopause.

It is worth mentioning that local treatment of VVA is not associated with the possible risks of systemic HRT. Among the reasons for not seeking treatment for VVA complaints are cultural ones and an understandable reluctance to discuss such issues, particularly with a male doctor. On the other hand, doctors also fail to inform about the possibilities of treatment for atrophic vaginal symptoms. ${ }^{5}$
Phytoestrogens are plant-derived chemical substances structurally or functionally similar to estradiol. The main phytoestrogen used as a treatment for women in the climacteric are isoflavones, polyphenolic flavonoids found naturally in plants such as Glycine max (L.) Merr and Trifolium pratense $\mathrm{L} .{ }^{6}$ Isoflavones contain a phenolic ring in a position analogous to estradiol, which allows them to occupy their receptors in different tissues, and may present actions similar to endogenous estrogen. ${ }^{7}$

Isoflavones have been used topically to prevent and delay skin aging in postmenopausal women. They act on the skin inhibiting tyrosine kinase, preventing the expression of mRNA encoding collagenases and elastases (metalloproteinases), and thus hindering the degradation of extracellular matrix fibers. Topical use of isoflavones in the skin can lead to epidermal proliferation, increased synthesis, and decreased enzymatic degradation of dermal collagen., ${ }^{8,9}$

To date, studies analyzing the effects of isoflavones derived from dry extract of Glycine $\max (\mathrm{L}$.) Merr, administered vaginally on vaginal epithelium, on morphometric features, the behavior of estrogen receptors, the vaginal flora, and endometrium are scarce. Research was conducted with postmenopausal women comparing the effects of isoflavones derived from dry extract of Glycine max (L.) Merr, conjugated equine estrogens and placebo administered vaginally on the vaginal epithelium and endometrium. As a result, there was improvement in the symptoms of vaginal atrophy with a significant increase in the values of cell maturation, similar to those obtained with conjugated estrogens, both superior to the placebo group. After treatment, in serum FSH and estradiol concentrations, none of the groups had an increase in endometrial thickness. ${ }^{10}$

Another study of the same product administered vaginally in another group of postmenopausal women evaluating the symptoms of vaginal dryness and dyspareunia, vaginal epithelial morphology, and estrogen re- 
ceptor expression, resulted in significant improvement of symptoms after treatment in the Treated Group compared with the Placebo Group, with increased vaginal epithelial thickness and percentage of immunopositive cells to estrogen receptors. ${ }^{11}$

As for the vaginal microbiota, we know that resident bacteria of the genital tract obtain the glycogen used in their nutrition from the local epithelium and, by producing lactic acid, they constitute a protective factor against the proliferation of pathological bacteria. The concentration of glycogen available for this microbiota depends on the developmental conditions of the urogenital epithelium, including the presence of estrogenic hormones, among other factors. Therefore, the hypoestrogenism typical of the climacteric phase allows a pathological microbiota to develop. The analysis of the vaginal microbiota is thus a tool for understanding the health condition of the urogenital tract. There are unsatisfactory attempts to improve urogenital health with hormone therapy and oral therapy with phytoestrogens, but these approaches are associated with the presence of adverse reactions and unconfirmed therapeutic outcomes, respectively. On the other hand, the application of phytoestrogens vaginally appears to be satisfactory due to the possibility of local action with little systemic interaction and a pharmacodynamics typical of phytomedicines. We highlight a pioneering study that evaluated the vaginal flora of women treated with isoflavones derived from Glycine $\max$ (L.) Merr, for the purpose of alternative (vaginal) route of phytoestrogens.

A study was conducted on the effects of isoflavones derived from Glycine max (L.) Merr on the vaginal microbiota of postmenopausal women who did not present systemic symptoms, had the exclusive complaint of vaginal atrophy, and applied topically a gel with the active product for 90 days, compared with a placebo. Vaginal $\mathrm{pH}$, serum concentration of estradiol and symptoms of genital atrophy were also analyzed.

The microbiota found in both groups was similar at T0, T30 and T90 days, with the prevalence of acidophilic species, namely coagulase-negative Staphylococcus, Enterococcus sp, Escherichia coli and Bacillus sp, with variation in the isoflavones group. Regarding vaginal $\mathrm{pH}$, there was a statistically significant reduction in T30 and T90 in the isoflavones group, which did not occur in the placebo group. As for FSH, there was no significant difference in the times studied. With respect to the Questionnaire on
Symptoms of Urogenital Atrophy, it was observed that in the isoflavones group there was improvement in all symptoms while in the placebo group only dryness and pruritus improved after 90 days of treatment. Thus, vaginal isoflavones appear to be an important alternative for the treatment of symptoms of genital atrophy in postmenopausal women, including those with contraindications to hormonal therapy, resulting in vaginal $\mathrm{pH}$ close to that of women of reproductive age, an increase in acidophilic species, including those potentially pathogenic - without causing infection - and improved urogenital health. ${ }^{12}$

Isoflavones administered vaginally present as an important alternative for the treatment of the symptom of genital atrophy thus constituting a new frontier within gynecology.

\section{References}

1. The North American Menopause Society. Menopause practice: A clinician's guide. 4. ed. Mayfield Heights: NAMS; 2010

2. Parish SJ, Nappi RE, Krychman ML, Kellogg-Spadt S, Simon JA, Goldstein JA, et al. Impact of vulvovaginal health on postmenopausal women: a review of surveys on symptoms of vulvovaginal atrophy. Int J Womens Health. 2013; 5:437-47.

3. Archer DF. Efficacy and tolerability of local estrogen therapy for urogenital atrophy. Menopause. 2010; 17(1):194-203.

4. Sturdee DW, Panay N; International Menopause Society Writing Group. Recommendations for the management of postmenopausal vaginal atrophy. Climacteric. 2010; 13(6):509-22.

5. Portman DJ, Gass ML; Vulvovaginal Atrophy Terminology Consensus Conference Panel. Genitourinary syndrome of menopause: new terminology for vulvovaginal atrophy from the International Society for the Study of Women's Sexual Health and the North American Menopause Society. Menopause. 2014; 21(10):1063-8.

6. Alves DL, Lima SMRR, Silva CR, Galvão MA, Shanaider A, Prado RAA, et al. Effects of Trifolium pratense and Cimicifuga racemosa on the endometrium of Wistar rats. Maturitas. 2008; 61(4):364-70.

7. Chen MN, Lin CC, Liu CF. Efficacy of phytoestrogens for menopausal symptoms: a meta-analysis and systematic review. Climacteric. 2015; 18(2):260-9.

8. Accorsi Neto AC. Efeitos histomorfométricos da isoflavona na pele de mulheres na pós-menopausa [thesis]. São Paulo: Escola Paulista de Medicina da Universidade Federal de São Paulo; 2005.

9. Moraes ARB, Haidar MA, Soares Júnior JM, Simões MJ, Baracat EC, Patriarca MT. The effects of topical isoflavones on postmenopausal skin: doble-blind and randomized clinical trial of efficacy. Eur J Obstet Gynecol Reprod Biol. 2009; 146(2):188-92.

10. Lima SMRR, Yamada SS, Reis BF, Postigo S, Silva MALG, Aoki T. Effective treatment of vaginal atrophy with isoflavone vaginal gel. Maturitas. 2013; 74(3):252-8.

11. Lima SMRR, Bernardo BFA, Yamada SS, Reis BF, Dutra GM, Galvão MAL. Effects of Glycine max (L.) Merr. soy isoflavone vaginal gel on epithelium morphology and estrogen receptor expression in postmenopausal women: a 12-week, randomized, double-blind, placebo-controlled trial. Maturitas. 2014; 78(3):205-11

12. de Biazi Andreotti JD, Lima SMRR, Endo CM, Franco B, Bernardo A, Scorzelli AC, et al. Estudo da microbiota vaginal em mulheres após a menopausa com o uso de isoflavonas via vaginal. Arq Med Hosp Fac Cienc Med Santa Casa São Paulo. 2014; 59(3):110-6 